\title{
Effects of laryngeal features on vowel duration: implications for Winter's Law
}

\author{
Chelsea SANKer
}

Brown University

\begin{abstract}
Vowels are longer before voiced than voiceless obstruents in many languages. Work on how this effect interacts with aspiration has been limited. This study presents data from Hindi and Telugu on vowel duration and other acoustic characteristics as influenced by following consonants. Hindi vowels were significantly longer before voiced stops than voiceless stops, with no significant effect of aspiration. Telugu vowels were only slightly longer before voiced than voiceless stops; more crucially, they were shorter before aspirated stops than unaspirated stops. The Telugu results provide a parallel demonstrating the phonetic plausibility of the sound change proposed in Winter's Law, with vowel lengthening before voiced unaspirated stops but not before voiced aspirated stops in Proto-BaltoSlavic. While the exact processes causing the voicing and aspiration effects remain unclear, this data contributes to evaluating the phenomenon. Phonetic differences between in Hindi and Telugu may also suggest characteristics of how the Proto-Balto-Slavic stop contrasts were realized.
\end{abstract}

\section{Introduction}

Vowels are generally longer before voiced than voiceless obstruents. Many studies have demonstrated that the effect is very large within English (e.g. House \& Fairbanks 1953; Peterson \& Lehiste 1960; Chen 1970). It is also significant in many other languages, e.g. German (Braunschweiler 1997; Fourakis \& Iverson 1984), Dutch (Warner et al. 2004), French (AbdelliBeruh 2003; Chen 1970), Lithuanian (Campos-Astorkiza 2012), Russian (Chen 1970), Armenian (Maddieson 1977), Georgian (Beguš 2017), Hindi (Durvasula \& Luo 2014; Ohala \& Ohala 1992), Marathi (Maddieson 1977), Bengali (Mikuteit \& Reetz 2007; Maddieson 1977), Assamese (Maddieson 1977), Kannada (Savithri 1986), Korean (Chen 1970), and Japanese (Port et al. 1980; Yoneyama \& Kitahara 2014), among others. 
There is variation in the degree of the effect in different languages, even among languages in which it is significant (Chen 1970). Some languages have a negligible effect, e.g. Polish and Czech (Keating 1979), Arabic (Mitleb 1984), and possibly Telugu (Reddy 1988). The effect can be weaker in some environments than in others; within English, Davis \& Summers (1989) found that there was a strong voicing effect in stressed vowels, but a less consistent effect among unstressed vowels, and Umeda (1975) found that the effect was large in syllables immediately before a pause, but much smaller elsewhere.

Studies on how the effect of voicing interacts with aspiration have varied results and have not been reported in a large number of languages. Some studies on languages with an aspiration contrast and a voicing contrast report voicing effects on vowel duration without addressing potential effects of aspiration (e.g. Mikuteit \& Reetz 2007); there may be a bias to not report comparisons between vowel durations before aspirated and unaspirated stops when there is no difference, so data on the absence of a difference might be underrepresented in the literature.

Hindi is the language best represented within work on aspiration effects, and demonstrates a potential limitation in interpreting results for languages with less data. There is variation across studies: Durvasula \& Luo (2014) and Maddieson \& Gandour (1976) found longer vowels before aspirated stops than unaspirated stops, both among voiced and voiceless stops, while Ohala \& Ohala (1992) found no consistent difference in either voicing category. The differences might reflect variations in experimental design across studies or differences across speakers.

Data on effects of aspiration on vowel duration also exist for a few other languages. Maddieson (1977), in a survey of five languages that allow word-final aspirated stops (Assamese, Bengali, Hindi, Marathi, Eastern Armenian), found that there is a general tendency for vowels to be longer before aspirated stops than before unaspirated stops, though some languages did not have a significant overall difference. In Kannada, vowels were also longer before aspirated stops than before unaspirated stops, but the effect of aspiration was stronger and more consistent among voiceless stops (Savithri 1986).

\subsection{Possible explanations}

\subsubsection{Phonetic sources}

The source of the voicing effect on vowel duration remains in question. Explanations have been proposed based on articulation (e.g. Chen 1970; 
Halle \& Stevens 1967) and perception (e.g. Kluender et al. 1988; Javkin 1976), and both may play a role. Any perceptually-driven effect is only possible if there is an existing difference based on production.

Javkin (1976) suggested a perceptual effect resulting from listeners misinterpreting the boundary between the vowel and following closure, based on voicing being maintained throughout. Lengthening as a result of ambiguous boundaries would predict a similar effect of preceding consonants on vowel duration; some studies have found this effect (Mohr 1971; Port et al. 1980), though others have not (Peterson \& Lehiste 1960; Umeda 1975). This explanation might also predict greater vowel duration in environments with more similar noise patterns in the vowel and the neighboring consonant. However, while vowels are longer before fricatives than before stops (Umeda 1975; House \& Fairbanks 1953), they are not generally longer before sonorants than before obstruents (House \& Fairbanks 1953; Umeda 1975).

Another possible explanation is compensatory timing of neighboring segments, as voiced obstruents often have shorter constrictions than voiceless obstruents. Some studies have found a negative correlation between vowel duration and the duration of a following consonant, after controlling for voicing differences, but it varies by language (Port et al. 1980). An inverse relationship between vowel duration and stop closure duration is also reflected in shorter vowel durations before geminate consonants than before singletons (Maddieson 1985).

Kluender et al. (1988) suggest that the inverse correlation between vowel duration and consonant duration is a perceptual effect, with vowels sounding longer in the context of a shorter consonant. However, Fowler (1992) found evidence against this explanation; at least among English speakers, longer closures increased identifications of preceding vowels as long, rather than decreasing them. It is possible that this result simply reflected a lack of this perceptual compensation among English speakers, and is not necessarily indicative of what perceptual patterns speakers of different languages might exhibit.

There might instead be a compensatory timing effect in production. Fowler (1981) proposes that the articulatory timing of consonants is overlaid on the timing of the broader vowel gestures, so a longer consonant shortens the vowel because coarticulation with the consonant obscures the vowel constriction. However, the total duration of vowel + consonant is not consistent with voiced and voiceless consonants (Port et al. 1980; Mikuteit \& Reetz 2007), and vowels are longer before fricatives than before stops even though fricatives are generally longer than stops (Umeda 1977). The duration patterns cannot result simply from consonant ges- 
tures overlaid on the same vowel gestures, but relative timing suggests that they do contribute in part to the duration effects (de Jong 1991).

If a compensatory timing instead involved the total duration of the stop closure + aspiration, it would predict shorter vowels before aspirated stops; however, most studies have found that vowels are longer before aspirated stops than before unaspirated stops (e.g. Maddieson 1977; Durvasula \& Luo 2014). On the other hand, the closure of voiced unaspirated stops is longer than in voiced aspirated stops (Schiefer 1992; Dutta 2003), so compensatory timing of stop closure and preceding vowel duration would predict longer vowels before voiced aspirated stops. Both compensatory timing patterns might be possible.

Vowels have a range of acoustic differences influenced by voicing of the following consonant, many of which have been demonstrated to affect identifications of the voicing of a consonant (Lisker 1986). It is not clear whether they are contributing to the perception of greater vowel length before voiced obstruents, or if they are reflecting articulatory differences that might also underlie the duration differences.

F0 is higher before voiceless consonants than before voiced consonants (e.g. Kohler 1982), though some studies have not found this difference (e.g. Mohr 1971; Gruenenfelder \& Pisoni 1980). The difference is more reliably found as an effect of prevocalic consonants (e.g. House \& Fairbanks 1953; Kong et al. 2012). There is also a greater F0 drop caused by breathy voice than modal voice, both as an inherent quality of vowels (Hombert et al. 1979) and as an effect of neighboring aspiration (Dutta 2003; Cohn \& Lockwood 1994). Lower steady-state F0 and lower F0 at the vowel offset result in a larger number of judgements that a following stop is voiced (e.g. Castleman \& Diehl 1996; Gruenenfelder \& Pisoni 1980). Rising contours exhibit mixed perceptual results; they have both been found to increase [-voice] identifications (Kohler 1985) and to increase [+voice] identifications (Derr \& Massaro 1980).

F0 contours can make vowels seem longer (e.g. Yu 2010; Lehiste 1976), so the F0 drops created by voicing could produce perceived lengthening. However, the effect varies based on environment; van Dommelen (1993) found the pattern only within isolated monosyllabic words, but it interacted with other prosodic factors in longer utterances, which could eliminate or even reverse the effect. Higher F0 increases the perceived length of vowels, though production has the opposite pattern (Yu 2010; Gussenhoven \& Zhou 2013), so the duration predictions made by the absolute scale of $\mathrm{F} 0$ are ambiguous.

Spectral tilt (H1-H2) is higher for vowels next to voiceless stops than next to voiced stops, in English and Japanese (Kong et al. 2012) and Geor- 
gian (Vicenik 1975); this likely in part reflects breathiness resulting from voiceless stops being aspirated in the languages investigated. Perceptually, spectral tilt can be used as a cue for laryngeal contrasts, e.g. in Korean (Kim et al. 2002), though it is not clear how much it is used as a cue crosslinguistically for different laryngeal contrasts.

F1 is lower before voiced consonants than before voiceless consonants, both within the steady portion of the vowel, and particularly at the transition into the consonant (Summers 1987), though the degree of the effect can depend on the speaker's native language (Crowther \& Mann 1992). The F1 differences are also used as perceptual cues, with [+voice] identifications more likely when F1 is lower (Summers 1988; Benkí 2001).

The closing gestures transitioning from vowels into voiced consonants take longer than closures for voiceless consonants, which is reflected both in articulation and acoustics (Summers 1987; de Jong 1991). This has been explained as the result of voiced obstruents requiring more complex laryngeal readjustment (Halle \& Stevens 1967) or additional openingclosing gestures (Goldstein \& Browman 1986), or as the result of voiceless stops requiring more force to achieve closure, which leads to greater velocity (Chen 1970). The difference in transition durations is also reflected in perception experiments; longer transitions result in more [+voice] identifications of consonants (Benkí 2001; Stevens \& Klatt 1974).

\subsubsection{Phonologization and vowel length}

Given a phonetic source for a duration difference, how do languages develop distinct patterns in the degree of the effect? Variation in the size of the effect across languages suggests some degree of phonologization.

The voicing effect can be preserved even in environments in which the voicing contrast is eliminated or extremely altered in realization, e.g. before (devoiced) word-final obstruents in German (Fourakis \& Iverson 1984) and in whispered English (Sharf 1964). Such patterns suggest phonologization of the duration pattern in these languages. On the other hand, there are other languages in which the effect is lost in voicing neutralization environments, e.g. with voicing assimilation in French (AbdelliBeruh 2003) and with final devoicing in Dutch (Warner et al. 2004).

Previous work that has included vowels of different inherent durations has generally found a similar effect across different vowels, though sometimes the effect is consistent as a proportion of the vowel duration, and sometimes it is consistent in absolute size. Whether the voicing effect is consistent across contexts or varies as a ratio of the duration of the vowel might be an indicator of whether the effect is phonologized; when 
the effect is mechanically driven, the size should be consistent regardless of what percentage of the vowel this difference ends up being, while a phonologized pattern can target a particular ratio (Solé 2007).

Studies comparing voicing effects across vowel heights and between tense and lax vowels have found voicing effects of proportionally similar size across vowels in English, though there is some variability by vowel and environment (Peterson \& Lehiste 1960; House 1961; Luce \& CharlesLuce 1985). The effect is also proportionally similar in vowels lengthened by phonological stress or syntactic focus (de Jong 2004) or by phrase-final lengthening (Cooper \& Danly 1981). A similarly proportional voicing effect has also been found in German (Braunschweiler 1997).

In contrast, there is no proportional expansion of the voicing effect in longer vowels in Arabic, in which it is weak (e.g. Mitleb 1984; Flege $\&$ Port 1981). The absolute values of the weak voicing effects are consistent between long and short vowels (Port et al. 1980) and between stressed and unstressed syllables, while the duration differences between phonologically long and short vowels are expanded in stressed syllables (de Jong \& Zawaydeh 2002). Warner et al. (2004) also found a voicing effect of equivalent absolute size in long and short vowels in Dutch, which has a slightly larger voicing effect overall.

In Japanese, the voicing effect was proportionally slightly smaller in longer vowels, though it was significant across vowels and partially scaled up relative to the duration of the vowel, both across phonological lengths and across vowel heights (Yoneyama \& Kitahara 2014). In Lithuanian, the effect also scaled up somewhat with longer vowels, while being smaller in relative size within longer vowels (Campos-Astorkiza 2012).

Some work has suggested that the voicing effect is weaker in languages with phonological vowel length (e.g. Keating 1985; Buder \& Stoel-Gammon 2002). Consistent with the voicing effect being less pronounced when it competes with a phonological length contrast, Campos-Astorkiza (2012) found that in Lithuanian, the voicing effect was strongest for the one vowel quality for which there is no length contrast (e:).

\subsection{Winter's Law}

Clarifying the effects of voicing and aspiration on vowel duration can also inform our understanding of phonological changes that have been proposed for reconstructed languages. While I aim to contribute to explaining these effects, I focus on using data from modern languages to establish some of the range of possible effects that might occur diachronically. In 
particular, the effects of voiced aspirated stops in modern languages like Hindi and Telugu can help test the phonetic plausibility of Winter's Law.

Winter (1978) proposed that short vowels in Proto-Balto-Slavic were lengthened before voiced unaspirated stops, but not before voiced aspirated stops. This rule explains many cases of reflexes indicating long vowels in phonological and morphological environments where they would not otherwise be expected. The law is widely accepted (Jasanoff 2017), sometimes with additional restrictions on the conditioning environment (e.g. Shintani 1985; Rasmussen 1992; Matasović 1995). Kortlandt (1977, 1988) takes the law as evidence for the Glottalic Theory of PIE stops, in which the mediae were contrastively glottalized, not voiced unaspirated (Hopper 1973; Gamkrelidze \& Ivanov 1973).

However, the law is debated, and some scholars reject it (e.g. Gercenberg 1981:129-138; Campanile 1994), based on the presence of counterexamples and the existence of other plausible explanations for some examples. Patri (2005) provides a summary of papers in favor of and against the law; he objects that there are too many exceptions to the law and that it is not a real phenomenon. Proponents of Winter's Law point out that the possibility of other explanations for some forms and the presence of some exceptions do not disprove the law, as it is certainly not responsible for all long vowels in Proto-Balto-Slavic; some are clearly due to lengthened grades or laryngeals (Matasović 1995; Rasmussen 1992:530), and some are likely to be loanwords (Kortlandt 2009).

There are some exceptions to the rule as originally formulated, which Winter himself acknowledges. Various proposals have been made to limit the rule to particular environments based on segments or prosody, though none of these revisions have been fully accepted, and all of these formulations still have some exceptions that they do not capture (Jasanoff 2017).

Shintani (1985) proposed that the lengthening only took place in unstressed pretonic syllables; this formulation is largely accepted and partially revised by Rasmussen (1992), who also provides further examples supporting the law. Cross-linguistically, lengthening is more likely in stressed syllables than unstressed syllables, rather than less likely (e.g. Davis \& Summers 1989). Rasmussen (1992:538) suggests that voicing-conditioned lengthening was not phonemicized in this environment, because stressed vowels were all phonetically lengthened regardless of the following consonant; this explanation could be plausible if the voicing effect was consistent in absolute size, as in Arabic (de Jong \& Zawaydeh 2002), rather than being proportional to the length of the vowel, as in English (de Jong 2004). Matasović (1995) proposes that the effect only occurred when the 
consonant was a coda, which would be consistent with phonetic data on the size of the voicing effect in different environments (Umeda 1975).

Aside from issues of particular words being apparent exceptions to the law, it has been questioned whether the law is phonetically natural given the standard phonetic values of the PIE stop series, with the mediae as voiced unaspirated stops and the mediae aspiratae as voiced aspirated stops (Shintani 1985; Kortlandt 1988; Rasmussen 1992). In particular, it is unclear whether the effect of voicing on the duration of preceding vowels can be restricted based on aspiration, as the limited data on interactions between voicing and aspiration suggest that vowels before voiced aspirated stops are equal in length or longer than vowels before voiced unaspirated stops (Maddieson 1977; Durvasula \& Luo 2014). However, other aspects of the law are consistent with observed phonetic patterns, including the well-attested pattern of greater vowel duration before voiced stops than before voiceless stops. Winter (1978) also describes the lengthening as occurring when a sonorant intervened, which is consistent with observations about the voicing effect in modern languages (e.g. Chen 1970; Raphael et al. 1975).

In this study, I investigate whether there are modern parallels for a voicing effect in which vowels are longer before voiced unaspirated stops than before voiced aspirated stops. I investigate two languages which both have contrastive series of voiced aspirated and voiced unaspirated stops: Hindi and Telugu (both also have voiceless aspirated and voiceless unaspirated stops). While a lack of parallel within the languages investigated would not necessarily demonstrate the phonetic impossibility of this pattern, the presence of the pattern would confirm the possibility. A modern parallel does not prove that the Winter's Law was a real rule, but it certainly strengthens the other evidence and also provides support for the standard phonetic values of the PIE stops series.

\section{Methods}

Three native speakers of Hindi and two native speakers of Telugu participated in this study, all members of the Brown University community. All of them were also fluent speakers of English.

Subjects produced VC and VCV nonce words in isolation, elicited in randomized order based on written stimuli, presented in PsychoPy (Pierce 2007), and were recorded in a quiet room at a $44.1 \mathrm{kHz}$ sampling rate with a Yeti desktop microphone. Hindi forms were presented in devanagari. Telugu forms were presented in both the Telugu script and ISO Roman- 
ization, because the speakers, while fluent in spoken Telugu, had some concerns about their level of experience with written Telugu.

Stimuli included each combination of the long and short versions of the vowels /u/, /a/, /i/ (in Hindi, they also have quality differences) followed by the consonants / $\mathrm{p}, \mathrm{p}^{\mathrm{h}}, \mathrm{b}, \mathrm{b}^{\mathrm{h}}, \mathrm{t}, \mathrm{t}^{\mathrm{h}}, \mathrm{d}, \mathrm{d}^{\mathrm{h}}, \mathrm{t}, \mathrm{t}^{\mathrm{h}}, \mathrm{d}, \mathrm{d}^{\mathrm{h}}, \mathrm{k}, \mathrm{k}^{\mathrm{h}}, \mathrm{g}, \mathrm{g}^{\mathrm{h}}, \mathrm{m}, \mathrm{n}$, $\eta, s, s, \int /$. Each combination was produced both as a VC form and also as a VCV form with a final /a/ and /a:/.

This resulted in 414 forms produced by each speaker. Some vowels were lengthened due to hesitations and corrections; disfluencies and unclear utterances were omitted from analysis. For Hindi, VCV forms were omitted from analysis. Telugu VC forms were often realized with an excrescent final vowel, as word-final stops are not phonologically permitted, so all environments were included in analysis.

The forms were analyzed in Praat (Boersma \& Weenink 2017). Vowel boundaries were defined by the presence of voicing as well as visible first and second formants; boundaries with following sonorants were based on sharp transition points in the formant patterns.

\section{Duration results}

\subsection{Vowels before stops}

The mean duration for Hindi vowels of each phonological length and stop environment are given in Table 1; the length contrast is also reflected in tense/lax differences. Vowels were significantly longer before voiced stops than before voiceless stops (cf. Maddieson \& Gandour 1976; Ohala \& Ohala 1992; Durvasula \& Luo 2014). There was no clear effect of aspiration, either among voiced or voiceless stops. The lack of effect of aspiration is consistent with some previous work (Ohala \& Ohala 1992), though other studies have found longer vowels before voiced aspirated stops (Maddieson \& Gandour 1976; Durvasula \& Luo 2014).

\begin{tabular}{lcccc}
\hline \hline & voiced & voiced asp. & voiceless & voiceless asp. \\
\hline Long vowels & 253.8 & 255.8 & 206.0 & 214.8 \\
Short vowels & 148.1 & 147.7 & 126.6 & 124.5 \\
\hline \hline
\end{tabular}

Table 1: Hindi vowel durations (ms), by following consonant type

The proportional size of the voicing effect for Hindi was consistent between long vowels (254.8 ms vs. $210 \mathrm{~ms}$, ratio 1.21 ) and short vowels (147.9 ms vs. $125.6 \mathrm{~ms}$, ratio 1.18). Within long vowels, there was a weak trend towards greater length before aspirated stops than before un- 
aspirated stops ( $237.3 \mathrm{~ms}$ vs. $231.2 \mathrm{~ms}$ ), but no clear difference between aspiration environments among short vowels (135.9 ms vs. $136.7 \mathrm{~ms}$ ).

Table 2 provides a summary of a mixed effects model for predictors of vowel duration in Hindi. The strongest predictor was phonological length. The voicing effect was also apparent within this model, as well as difference between vowel qualities.

\begin{tabular}{lcccc}
\hline \hline & Estimate & Std. Error & t value & p value \\
\hline \hline (Intercept) & 165.5 & 7.22 & 22.91 & $<0.0001$ \\
Length-Long & 94.8 & 3.54 & 26.76 & $<0.0001$ \\
Voi-Voiceless & -35.3 & 4.81 & -7.33 & $<0.0001$ \\
Asp-Aspirated & 1.6 & 4.92 & 0.33 & 0.74 \\
Vowel-i & -14.1 & 4.43 & -3.20 & 0.0015 \\
Vowel-u & -21.6 & 4.19 & -5.17 & $<0.0001$ \\
VoiVoiceless:AspAspirated & 2.79 & 7.03 & 0.40 & 0.69 \\
\hline \hline
\end{tabular}

Table 2: Mixed effects model for phonological predictors of Hindi vowel duration. Intercept : Length = Short; Voicing = Voiced; Aspiration = Unaspirated; Vowel = /a/

Telugu vowels exhibited a different duration pattern than Hindi vowels. There was a weaker effect of voicing, consistent with the negligible effect reported by Reddy (1988). More strikingly, there was a significant effect of aspiration. Vowels were shorter before aspirated stops than unaspirated stops, which was most apparent within voiced stops. The mean duration for vowels in each category are given in Table 3. This is an important result in the light of the pattern which is assumed in Winter's Law.

\begin{tabular}{lcccc}
\hline \hline & voiced & voiced asp. & voiceless & voiceless asp. \\
\hline Long vowels & 307.3 & 287.7 & 288.3 & 273.4 \\
Short vowels & 116.7 & 103.6 & 102.2 & 102.3 \\
\hline \hline
\end{tabular}

Table 3: Telugu vowel durations (ms), by following consonant type

The voicing effect for Telugu was of a similar absolute size for phonologically long vowels (293.2 ms vs. $281.7 \mathrm{~ms}$, ratio 1.04) and short vowels (110.2 ms vs. $102.3 \mathrm{~ms}$, ratio 1.08), though it was slightly larger within long vowels. The effect of following aspiration was proportionally similar among long vowels (279.1 ms vs. $295.1 \mathrm{~ms}$, ratio 0.95) and among short vowels (103.0 ms vs. $110.9 \mathrm{~ms}$, ratio 0.93). However, the aspiration pattern in short vowels was only present before voiced stops, while among long vowels there was a difference both before voiced and voiceless stops. 
Table 4 provides a summary of a mixed effects model for predictors of vowel duration in Telugu. The strongest predictor was phonological length, with a larger difference between long and short vowels than was found in Hindi. The aspiration effect seen in the means is also apparent in this model. Vowels were longer before voiced stops than before voiceless stops, but the difference was only marginally significant. There were also significant differences between vowel qualities.

\begin{tabular}{lcccc}
\hline & Estimate & Std. Error & t value & p value \\
\hline \hline (Intercept) & 139.2 & 16.88 & 8.25 & 0.029 \\
Length-Long & 180.8 & 6.05 & 29.91 & $<0.0001$ \\
Voi-Voiceless & -14.7 & 8.39 & -1.75 & 0.081 \\
Asp-Aspirated & -15.7 & 7.97 & -1.97 & 0.05 \\
Vowel-i & -27.0 & 7.44 & -3.63 & 0.00031 \\
Vowel-u & -13.8 & 7.62 & -1.81 & 0.071 \\
VoiVoiceless:AspAspirated & 7.5 & 11.66 & 0.65 & 0.52 \\
\hline \hline
\end{tabular}

Table 4: Mixed effects model for phonological predictors of Telugu vowel duration. Intercept: Length = Short; Voicing = Voiced; Aspiration = Unaspirated; Vowel = /a/

This work replicates previous results in the effect of stop voicing on preceding vowels in Hindi, and presents new data on the weaker effect in Telugu. The differences between Hindi and Telugu in the size of the voicing effect and in how it compares across vowel lengths might suggest that it is phonologized in the former and not the latter. The aspiration effect in Telugu, in addition to being significant, also scales up with vowel duration, which could also suggest that it is phonologized.

\subsection{Vowels before sonorants}

There is disagreement about whether the voicing effect is caused by shortening before voiceless obstruents (e.g. Klatt 1976; Keating 1985) or by lengthening before voiced obstruents (e.g. Halle \& Stevens 1967; Gandour et al. 1980). Vowels before sonorants can provide additional evidence. When this comparison is reported, vowel durations before sonorants tend to pattern with vowels before voiced obstruents, though there is some variation based on the segments and the context, including cases in which vowels are longer before sonorants than before voiced obstruents (House \& Fairbanks 1953; Umeda 1975), so it is not clear that sonorants provide an absolute baseline for vowel duration. Nonetheless, they probably provide the most neutral environment for comparison. 
In Hindi, sonorant environments do not align with either voiced or voiceless stop environments. Long vowels before sonorants pattern more like vowels before voiced stops, but are somewhat intermediate $(240.2$ ms; $254.8 \mathrm{~ms}$ before voiced stops, $210 \mathrm{~ms}$ before voiceless stops). Short vowels before sonorants pattern more like vowels before voiceless stops (131.3 ms; $147.9 \mathrm{~ms}$ before voiced stops, $125.6 \mathrm{~ms}$ before voiceless stops). These patterns might suggest that the voicing effect results from a combination of lengthening before voiced obstruents and shortening before voiceless obstruents, or that there is also an effect of sonorants on vowel duration, which interacts differently with phonological vowel length.

In Telugu, long vowels before sonorants have durations similar to those before voiced aspirated stops or voiceless unaspirated stops (290.7 ms; see Table 3 for the stop patterns), while short vowels before sonorants have duration similar to that of voiced unaspirated stops (118.7 ms; 116.7 $\mathrm{ms}$ before voiced unaspirated stops, 102.2-103.6 ms before other stops). Both patterns are consistent with aspiration having a shortening effect on preceding vowels, though they disagree in whether they suggest that the voicing effect is due to lengthening or shortening.

\section{Discussion of possible explanations}

\subsection{Closure and release durations}

Some work has proposed that the voicing effect is due to compensatory timing with the shorter duration of constriction in voiced obstruents than in voiceless obstruents, either in perception (Kluender et al. 1988) or production (Port et al. 1980). Some work has found a negative correlation between vowel duration and stop closure duration (e.g. de Jong 1991; Beguš 2017), though other work has found a negligible or positive correlation (e.g. Durvasula \& Luo 2014).

Table 5 presents the mean closure durations in stops of each category in Hindi. Using a linear mixed effects model, closures were significantly longer for voiceless stops than voiced stops $(p<0.001)$. Closures were also shorter after long vowels than after short vowels ( $\mathrm{p}<0.001)$, though the size of this effect was much smaller; this pattern has also been found elsewhere (Warner et al. 2004; Braunschweiler 1997). There was no effect of aspiration on the duration of stop closure $(p=0.94)$, nor an interaction between aspiration and voicing $(\mathrm{p}=0.17)$.

Table 6 presents correlations between vowel durations and stop closure durations within Hindi, separated by phonological vowel length and stop category. There was a trend towards negative correlation, but it 


\begin{tabular}{lcccc}
\hline \hline & voiced & voiced asp. & voiceless & voiceless asp. \\
\hline After long vowels & 81.0 & 85.4 & 144.8 & 140.8 \\
After short vowels & 103.2 & 99.3 & 158.9 & 143.9 \\
\hline \hline
\end{tabular}

Table 5: Hindi stop closure durations (ms)

only reached significance in two categories, both within long vowels. The trend was weaker among short vowels.

\begin{tabular}{lcccc}
\hline \hline & voiced & voiced asp. & voiceless & voiceless asp. \\
\hline Long vowels & -0.057 & $-0.28^{*}$ & $-0.32^{* *}$ & -0.069 \\
Short vowels & -0.17 & -0.25 & 0.049 & 0.038 \\
\hline
\end{tabular}

Table 6: Correlations between Hindi vowel duration and stop closure duration. N was approximately 61 in each group, with some variation due to errors and unreleased stops.

Table 7 presents correlations between vowel duration and total stop duration (closure + aspiration) in Hindi. While this comparison is not usually reported, there is no clear reason why compensatory timing could not include aspiration. Beguš (2017) found both duration of stop closure and aspiration to be significant predictors of vowel duration.

\begin{tabular}{lcccc}
\hline \hline & voiced & voiced asp. & voiceless & voiceless asp. \\
\hline Long vowels & -0.097 & -0.17 & $-0.34^{* * *}$ & -0.16 \\
Short vowels & 0.058 & 0.064 & -0.0008 & 0.23 \\
\hline \hline
\end{tabular}

Table 7: Correlations between Hindi vowel duration and total stop duration (closure + aspiration). $\mathrm{N}$ was approximately 61 in each group.

There was no consistent pattern in correlations between vowel duration and total stop duration, though there was a trend towards negative correlation among long vowels, which reached significance among voiceless unaspirated stops. Notably, this was also a category with a significant correlation between vowel duration and stop closure duration, so this correlation might be reflecting a relationship independent of aspiration.

Table 8 presents the mean closure durations in stops of each category in Telugu. Using a linear mixed effects model, closures were significantly longer for voiceless stops than voiced stops $(\mathrm{p}<0.001)$, though the difference was smaller than it was in Hindi. There was a marginally significant effect of duration of the preceding vowel, with a tendency for longer closures after short vowels $(p=0.069)$. There was no effect of aspiration ( $p$ $=0.93)$, nor interaction between voicing and aspiration $(p=0.36)$. 


\begin{tabular}{lcccc}
\hline \hline & voiced & voiced asp. & voiceless & voiceless asp. \\
\hline After long vowels & 80.4 & 76.2 & 117.4 & 107.0 \\
After short vowels & 85.8 & 87.7 & 118.0 & 114.5 \\
\hline
\end{tabular}

Table 8: Telugu stop closure durations (ms)

Table 9 presents correlations between vowel durations and stop closure durations within Telugu, separated by phonological vowel length and stop category. There was a trend towards positive correlation, particularly among long vowels, but it only reached significance for one comparison. This correlation parallels the results that Durvasula \& Luo (2014) obtained in Hindi; these patterns could result from variation in speech rate across the task.

\begin{tabular}{lcccc}
\hline \hline & voiced & voiced asp. & voiceless & voiceless asp. \\
\hline Long vowels & 0.20 & 0.19 & $0.45^{* * *}$ & 0.21 \\
Short vowels & -0.035 & 0.11 & 0.083 & 0.081 \\
\hline \hline
\end{tabular}

Table 9: Correlations between Telugu vowel duration and stop closure duration. N was approximately 64 in each group, with some variation due to errors and unreleased stops.

Table 10 presents correlations between vowel duration and total stop duration (closure + aspiration) in Telugu. Given the ambiguity of boundaries between aspiration and following vowels, aspiration was only measured in word-final stops; because of the frequency of excrescent final vowels, there were rather few tokens for these measurements.

\begin{tabular}{llccc}
\hline \hline & voiced & voiced asp. & voiceless & voiceless asp. \\
\hline Long vowels & -0.023 & 0.29 & 0.34 & 0.074 \\
Short vowels & $-0.66^{* * *}$ & $-0.49^{* *}$ & -0.24 & -0.34 \\
\hline \hline
\end{tabular}

Table 10: Correlations between Telugu vowel duration and total stop duration (closure + aspiration). $\mathrm{N}$ was approximately 17 in each group, with some variation due to errors and excrescent final vowels.

There was a strong trend for negative correlation among short vowels, which reached significance within some categories. Among long vowels, the trend was weaker and positive. The difference might suggest that there is a compensatory timing pattern in production, but that it operates on a limited temporal scale, such that the duration of long vowels goes beyond what is captured by the relationship. 


\subsection{Phonation and other acoustic qualities}

\subsubsection{Relationships between acoustic measures and stop features}

A range of acoustic characteristics in vowels have been found to align with voicing contrasts of following consonants, including e.g. F0 contour and F1 (Lisker 1986). Vowel durations can also differ by voicing type; nonmodal vowels are usually longer than their modal counterparts, if there is a difference (Gordon \& Ladefoged 2001). Some explanations of the voicing effect are associated with different acoustic characteristics, interpreted either as indicators of articulatory differences driving the effect, or as perceptual factors driving vowel duration differences. See Section 1.1.1 for a summary of acoustic correlates of voicing and aspiration.

Table 11 provides a summary of acoustic measures in vowels preceding stops of each type in Hindi. Table 12 provides a summary of acoustic measures in vowels preceding stops of each type in Telugu. These are of course not the only possible acoustic characteristics influenced by neighboring vowels, but are meant to cover most of the characteristics which have previously been identified as correlating with a voicing or aspiration contrast, or which are phonetically likely to align with stop features based on related patterns.

The acoustic results will be discussed together for both languages, to facilitate discussion of what is suggested by the similarities and the differences. F1 results (z-scored by participant and vowel) are collapsed across vowel qualities, based on them exhibiting similar patterns independently.

\begin{tabular}{lcccc}
\hline \hline & voiced & voiced asp. & voiceless & voiceless asp. \\
\hline F0 max (z-scored) & -0.11 & -0.0073 & 0.15 & -0.11 \\
peak time (\%) & 27.3 & 27.5 & 30.2 & 33.0 \\
F0 contour (z-scored) & 0.07 & 0.037 & -0.13 & 0.16 \\
F1 (z-scored) & -0.077 & -0.049 & 0.063 & 0.13 \\
spectral tilt (dB) & 3.7 & 5.4 & 3.3 & 2.1 \\
HNR & 9.3 & 9.5 & 6.9 & 7.2 \\
jitter (\%) & 1.58 & 1.76 & 2.4 & 2.64 \\
\hline \hline
\end{tabular}

Table 11: Hindi acoustic measures by following stop type

For each measure, significance is reported from a mixed effects model including phonological vowel length, vowel quality, voicing of the following stop, aspiration of the following stop, and the interaction between voicing and aspiration.

In Hindi, the maximum F0 was generally higher before voiceless stops than before voiced stops; within voiceless environments, F0 was lower 


\begin{tabular}{lcccc}
\hline \hline & voiced & voiced asp. & voiceless & voiceless asp. \\
\hline F0 max (z-scored) & -0.25 & -0.12 & 0.18 & -0.011 \\
peak time (\%) & 54.3 & 52.0 & 56.6 & 54.3 \\
F0 contour (z-scored) & 0.11 & -0.096 & 0.009 & 0.091 \\
F1 (z-scored) & -0.11 & -0.011 & 0.1 & -0.063 \\
spectral tilt (dB) & -2.4 & -3.3 & -1.5 & -1.2 \\
HNR & 8.6 & 8.0 & 7.4 & 7.4 \\
jitter (\%) & 2.1 & 2.04 & 2.61 & 2.67 \\
\hline \hline
\end{tabular}

Table 12: Telugu acoustic measures by following stop type

before aspirated stops, while within voiced environments, F0 was higher before aspirated stops. Neither the main effect of voicing ( $p=0.38)$ or aspiration ( $p=0.39)$ was significant; however, the interaction was significant $(p=0.03)$. Telugu exhibited a similar general pattern; there was no significant effect of voicing $(\mathrm{p}=0.34)$ or aspiration $(\mathrm{p}=0.18)$, but there was a marginally significant interaction between them $(p=0.071)$. F0 is generally lower in breathy vowels than modal vowels (Hombert et al. 1979), and the same pattern has been found as an effect of preceding aspiration, including within Hindi (Dutta 2003); this result suggests that vowels do not assimilate to the breathiness of following stops.

The F0 peak occurred earlier within the vowel when followed by a voiced stop than when followed by a voiceless stop in Hindi $(p=0.016)$, which is consistent with results from previous studies (House \& Fairbanks 1953; Kohler 1982). The peak was slightly later before voiceless aspirated stops than before voiceless unaspirated stops, but there was no significant main effect of aspiration $(\mathrm{p}=0.59)$ or interaction with voicing $(p=0.41)$. In Telugu, there was no significant effect of voicing $(p=0.5)$ or aspiration $(p=0.45)$, nor an interaction between them $(p=0.79)$.

In Hindi, there was a strong tendency for decreasing F0 within the vowel, likely because they were produced in isolation and thus were always phrase-final. The F0 contour was similar before voiced and voiceless stops $(\mathrm{p}=0.33)$. There was no main effect of aspiration $(\mathrm{p}=0.77)$, but within voiceless stop environments, there was a large difference between aspirated and unaspirated stops, with a steeper downward slope before unaspirated stops; the interaction was marginally significant ( $p=0.057$ ). In Telugu, voiced aspirated stops had a steeper falling F0 than occurred in other stop environments, while aspiration among voiceless stops had a small difference in the opposite direction, which resulted in marginally 
significant effects of voicing ( $\mathrm{p}=0.085)$, aspiration $(\mathrm{p}=0.059)$, and the interaction between them ( $p=0.065)$.

F1 in Hindi was significantly higher before voiceless stops than before voiced stops ( $\mathrm{p}<0.001$ ), which is consistent with previous work (Summers 1987; Benkí 2001). F1 was also higher before aspirated stops than before unaspirated stops, primarily reflected among voiceless stops; the main effect was not significant $(p=0.93)$, but the interaction with voicing approached significance $(\mathrm{p}=0.12)$. In Telugu, there was no main effect of voicing $(p=0.42)$ or aspiration $(p=0.23)$. F1 was higher before voiceless unaspirated stops than before voiced unaspirated stops, but among aspirated stops, vowels exhibited a weaker trend in the opposite direction; the interaction was significant ( $\mathrm{p}=0.045)$.

In Hindi, spectral tilt (H1-H2) had a significantly steeper rise before voiced stops than before voiceless stops $(\mathrm{p}=0.0047)$. Spectral tilt was also somewhat steeper before aspirated stops $(\mathrm{p}=0.1)$, which interacted with voicing ( $p=0.072)$; it was steepest before voiced aspirated stops. Given the HNR and F0 patterns, these values likely do not reflect breathiness. In Telugu, spectral tilt was consistently more negative than it was in Hindi. Spectral tilt was slightly closer to positive before voiceless stops than before voiced stops ( $p=0.34$ ), which is notably in the opposite direction of the voicing effect within Hindi. There was no main effect of aspiration ( $p=0.66)$; spectral tilt was slightly more steeply negative before voiced aspirated stops than before voiced unaspirated stops, but the interaction with voicing was not significant ( $p=0.25)$.

The harmonics-to-noise ratio (HNR) was lower before voiceless stops, indicating more aperiodic noise in this context. The difference between voicing environments was large in Hindi $(p<0.001)$; in Telugu, there was a weak trend in the same direction $(p=0.31)$. There was no clear effect of aspiration in Hindi $(\mathrm{p}=0.64)$, nor an interaction with aspiration ( $\mathrm{p}=$ $0.87)$. In Telugu, there was also no significant effect of aspiration $(p=0.5)$, nor an interaction with voicing $(\mathrm{p}=0.37)$.

There was more jitter before voiceless stops than before voiced stops, both in Hindi $(\mathrm{p}<0.001)$ and in Telugu (0.01); the difference was slightly larger in Hindi. There was no effect of aspiration on jitter either in Hindi (for the main effect, $p=0.21$; for the interaction with voicing, $p=0.83$ ) or in Telugu (for the main effect, $p=0.65$; for the interaction, $p=0.86$ ).

\subsubsection{Relationships between acoustic measures and vowel duration}

Which of these measures might be associated with durational differences? Acoustic differences in the realization of the four-way stop contrast in 
Hindi and Telugu and how these measures correlate with vowel duration within categories may help clarify why there are different effects of voicing and aspiration in the two languages.

Two acoustic characteristics were significant or marginally significant predictors of vowel duration in Hindi but not in Telugu: F1 and the timing of the F0 peak. Both features were also associated with the difference in voicing environment in Hindi but not in Telugu.

F1 was significantly higher before voiceless stops than before voiced stops in Hindi, with no significant effect in Telugu. Controlling for vowel quality, F1 was a significant predictor of vowel duration in Hindi when the features of the following stop were not included in the model $(p=0.0088)$; higher F1 was associated with shorter vowels. The effect was eliminated when stop features were included in the model $(p=0.31)$.

F0 peak timing was significantly earlier before voiced stops than before voiceless stops in Hindi, with no significant effect in Telugu. In Hindi, the timing of the F0 peak was also a marginally significant predictor of vowel duration in models that did not include stop features $(\mathrm{p}=0.083)$; later peaks were associated with shorter vowels, which might suggest that the peak is timed relative to the beginning of the vowel. The effect was eliminated when stop features were included in the model $(p=0.35)$.

The relationship between these characteristics and vowel duration seems to result entirely from their association with the consonantal environment, as both effects are eliminated in models which include features of the following stop. This suggests that these measures do not have a direct causal relationship with duration, but result from articulatory characteristics distinguishing voiced and voiceless stops in Hindi. The lack of contrast in these characteristics in Telugu indicates that there is languagespecific variation not just in how consonant voicing influences the duration of preceding vowels, but also in other aspects of the interaction.

In Telugu, F0 maximum was a significant predictor of vowel duration, both in a model that included features of the following stops $(\mathrm{p}<0.001)$ and in a model that did not ( $\mathrm{p}=0.0015)$; higher F0 was associated with longer vowels. There was a marginally significant interaction between voicing and aspiration as predictors of F0 maximum, with lower F0 before voiceless aspirated stops than before voiceless unaspirated stops and higher F0 before voiced aspirated stops than before voiced unaspirated stops. However, the same interaction was present in Hindi, in which F0 maximum was not a predictor of vowel duration. The differences might suggest that a relationship between vowel duration and F0 maximum has been phonologized in Telugu, based on higher F0 increasing perceived vowel duration (cf. Yu 2010; Gussenhoven \& Zhou 2013). 
Jitter and HNR were highly significant predictors of vowel duration in both Hindi and Telugu, both in models that included the laryngeal features of following stops and in models that did not ( $p<0.001$ for all models); higher HNR was associated with longer vowels, and higher jitter was associated with shorter vowels. Both in Hindi and in Telugu, jitter was significantly higher before voiceless stops than before voiced stops. HNR was significantly higher before voiced stops than before voiceless stops in Hindi, while the difference was not significant in Telugu. The consistent correlation between jitter and vowel duration suggests that it is articulatorily tied both to devoicing and vowel duration. The lack of significant difference in HNR between voiced and voiceless environments in Telugu suggests that while transitions to voicelessness often have increased aperiodic noise as a side effect, languages can differ in their timing of laryngeal gestures at these boundaries. A different articulation of the transition between a vowel into a following voiceless stop in Telugu could be responsible both for the smaller HNR difference between voiced and voiceless environments and also the smaller duration difference.

\section{Conclusion}

The Telugu vowel duration results demonstrate that it is possible for vowels to be longer before voiced unaspirated stops than before voiced aspirated stops, making Winter's Law phonetically plausible. While Telugu does not provide an exact parallel, given that it has a four-way stop contrast rather than a three-way stop contrast (which is traditionally assumed for Proto-Indo-European) and the voicing effect is weak, the result is still striking. Telugu also has a vowel system that parallels Proto-Indo-European, with a length contrast that is not reinforced by a tense/lax distinction.

The different interaction between voicing and aspiration in Hindi and Telugu demonstrates some of the possibilities of language-specific variation in realizations of phonologically analogous contrasts. These results could inform our understanding of the phonetic characteristics of the Proto-Indo-European voiced aspirates, if other modern languages with voiced aspirated stops have the same alignment of aspiration effects and acoustic correlates of aspiration.

These patterns also provide additional information to help evaluate the underlying explanation of the voicing effect, based on the different acoustic characteristics associated with vowels preceding each of the four stop categories in Hindi and Telugu and how these correlate with vowel duration within each environment. The results for voicing are most consistent with articulatory differences between consonantal environments 
driving both the vowel duration differences and also the acoustic differences, e.g. in jitter, HNR, and F1.

The aspiration effect in Telugu does not point as clearly to a particular explanation. It could reflect a perceptual effect of higher F0 in aspiration environments, given the correlation between F0 maximum and vowel duration, though it is notable that this correlation is the opposite of the relationship that has been found elsewhere with tonal contrasts (Gussenhoven \& Zhou 2013; Gandour 1977). It is also possible that the pattern can be explained as the result of compensatory timing between vowels and following stops, with aspiration included as part of stop duration.

Much work still remains to be done in order to clarify the effects of voicing and aspiration on preceding vowels, both to explain the observed effects and also to establish what patterns are cross-linguistically possible based on those underlying mechanisms.

\section{Comments invited}

PiHPh relies on post-publication review of the papers that it publishes. If you have any comments on this piece, please add them to its comments site. You are encouraged to consult this site after reading the paper, as there may be comments from other readers there, and replies from the author. This paper's site is here:

https://doi.org/10.2218/pihph.3.2018.2898

\section{Acknowledgements}

I would like to thank all of my participants for their patience and enthusiasm, and the audience members of the LaryngeFringe satellite workshop of the Third Edinburgh Symposium on Historical Phonology for thoughtful questions and comments that helped in developing this paper. 


\section{Author contact details}

Chelsea Sanker

Cognitive, Linguistic, \& Psychological Sciences

Brown University

190 Thayer St.

Providence, RI 02912

USA

chelsea_sanker@brown.edu

\section{References}

Abdelli-Beruh, Nassima B. 2003. The stop voicing contrast in French sentences: Contextual sensitivity of vowel duration, closure duration, voice onset time, stop release and closure voicing. Phonetica 61.201219.

Beguš, Gašper. 2017. Effects of ejective stops on preceding vowel duration. Journal of the Acoustical Society of America 142(4). 2168-2184.

Benkí, José R. 2001. Place of articulation and first formant transition pattern both affect perception of voicing in English. Journal of Phonetics 29. 1-22.

Boersma, Paul \& David Weenink. 2017. Praat: doing phonetics by computer [computer program]. version 6.0.30. http://www .praat .org/.

Braunschweiler, Norbert. 1997. Integrated cues of voicing and vowel length in German: A production study. Language and Speech 40(4). 353-376.

Buder, Eugene H. \& Carol Stoel-Gammon. 2002. American and Swedish children's acquisition of vowel duration: Effects of vowel identity and final stop voicing. Journal of the Acoustical Society of America 111(4). 1854-1864.

Campanile, Enrico. 1994. A proposito della lex Winter. In Palmira Cipriano, Paolo Di Giovine \& Marco Mancici (eds.), Miscellanea di studi linguistici in onore di Walter Belardi, 2: Linguistica indoeuropea e non indoeuropea, 339-351. Il Calamo.

Campos-Astorkiza, Rebeka. 2012. Length contrast and contextual modifications of duration in the Lithuanian vowel system. Baltic Linguistics 3. 9-41.

Castleman, Wendy A. \& Randy L. Diehl. 1996. Effects of fundamental frequency on medial and final [voice] judgements. Journal of Phonetics 24. 383-398. 
Chen, Matthew. 1970. Vowel length variation as a function of the voicing of the consonant environment. Phonetica 22.129-159.

Cohn, Abigail C. \& Katherine Lockwood. 1994. A phonetic description of Madurese and its phonological implications. Working Papers of the Cornell Phonetics Laboratory 9. 67-92.

Cooper, William E. \& Martha Danly. 1981. Segmental and temporal aspects of utterance-final lengthening. Phonetica 38. 106-115.

Crowther, Court S. \& Virginia Mann. 1992. Native language factors affecting use of vocalic cues to final consonant voicing in English. Journal of the Acoustical Society of America 92(2). 711-722.

Davis, Stuart \& W. Van Summers. 1989. Vowel length and closure duration in word-medial VC sequences. Journal of Phonetics 17. 339-353.

Derr, Marcia A. \& Dominic W. Massaro. 1980. The contribution of vowel duration, f0 contour, and frication duration as cues to the /juz/-/jus/ distinction. Perception \& Psychophysics 27(1). 51-59.

van Dommelen, Wim A. 1993. Does dynamic f0 increase perceived duration? New light on an old issue. Journal of Phonetics 21. 367-386.

Durvasula, Karthik \& Quian Luo. 2014. Voicing, aspiration, and vowel duration in Hindi. In Stellan Ohlsson \& Richard Catrambone (eds.), Proceedings of meetings on acoustics, 060009. Acoustical Society of America.

Dutta, Intranil. 2003. Correlation between Voicing Lead Time (VLT) and f0 lowering following breathy voiced stops in Hindi. In Proceedings from the annual meeting of the Chicago Linguistic Society, vol. 39 1, 405-422.

Flege, James Emil \& Robert Port. 1981. Cross-language phonetic interference: Arabic to English. Language and Speech 24(2). 124-146.

Fourakis, Marios \& Gregory K. Iverson. 1984. On the 'incomplete neutralization' of German final obstruents. Phonetica 41.140-149.

Fowler, Carol A. 1981. A relationship between coarticulation and compensatory shortening. Phonetica 38. 35-50.

Fowler, Carol A. 1992. Vowel duration and closure duration in voiced and unvoiced stops: There are no contrast effects here. Journal of Phonetics 20. 143-165.

Gamkrelidze, Thomas \& Vjaceslav Ivanov. 1973. Sprachtypologie und die rekonstruktion der gemeinindogermanischen verschlüsse. Phonetica 27. 150-156.

Gandour, Jack. 1977. On the interaction between tone and vowel length: Evidence from Thai dialects. Phonetica 34. 54-65.

Gandour, Jack, Bernd Weinberg \& Diane Rutkowki. 1980. Influence of postvocalic consonants on vowel duration in esophageal speech. Language and Speech 23(2). 149-158. 
Gercenberg, Leonard Georgievič. 1981. Voprosy rekonstruckcii indoevropejskoj prosodiki. Nauka.

Goldstein, Louis \& Catherine P. Browman. 1986. Representation of voicing contrasts using articulatory gestures. Journal of Phonetics 14. 339-342.

Gordon, Matthew \& Peter Ladefoged. 2001. Phonation types: A crosslinguistic overview. Journal of Phonetics 29. 383-406.

Gruenenfelder, Thomas M. \& David B. Pisoni. 1980. Fundamental frequency as a cue to postvocalic consonantal voicing: Some data from speech perception and production. Perception and Psychophysics 28(6). 514-520.

Gussenhoven, Carlos \& Wencui Zhou. 2013. Revisiting pitch slope and height effects on perceived duration. Proceedings of INTERSPEECH 2013: 14th Annual Conference of the International Speech Communication Association 1365-1369.

Halle, Morris \& Kenneth Stevens. 1967. On the mechanism of glottal vibration for vowels and consonants. MIT Research Laboratory of Electronics, Quarterly Progress Reports 85. 267-271.

Hombert, Jean-Marie, John J. Ohala \& William G. Ewan. 1979. Phonetic explanations for the development of tones. Language 55(1). 37-58.

Hopper, Paul. 1973. Glottalized and murmured occlusives in indoeuropean. Glossa 7(2). 141-166.

House, Arthur S. 1961. On vowel duration in English. Journal of the Acoustical Society of America 33(9). 1174-1178.

House, Arthur S. \& Grant Fairbanks. 1953. The influence of consonant environment upon the secondary acoustical characteristics of vowels. Journal of the Acoustical Society of America 25(1). 105-113.

Jasanoff, Jay. 2017. The prehistory of the Balto-Slavic accent. Brill.

Javkin, Hector R. 1976. The perceptual basis of vowel duration differences associated with the voiced/voiceless distinction. Report of the Berkeley Phonology Laboratory 1. 78-92.

de Jong, Kenneth. 1991. An articulatory study of consonant-induced vowel duration changes in English. Phonetica 48. 1-17.

de Jong, Kenneth. 2004. Stress, lexical focus, and segmental focus in English: Patterns of variation in vowel duration. Journal of Phonetics 32. 493-516.

de Jong, Kenneth \& Bushra Zawaydeh. 2002. Comparing stress, lexical focus, and segmental focus: Patterns of variation in Arabic vowel duration. Journal of Phonetics 30. 53-75.

Keating, Patricia. 1985. Universal phonetics and the organization of grammars. In Victoria A. Fromkin (ed.), Phonetic linguistics: Essays in honor of Peter Ladefoged, 115-131. Academic Press. 
Keating, Patricia A. 1979. A phonetic study of voicing contrast in Polish: Brown University dissertation.

Kim, Mi-Ryoung, Patrice Speeter Beddor \& Julie Horrocks. 2002. The contribution of consonantal and vocalic information to the perception of Korean initial stops. Journal of Phonetics 30. 77-100.

Klatt, Dennis H. 1976. Linguistic uses of segmental duration in English: Acoustic and perceptual evidence. Journal of the Acoustical Society of America 59(5). 1208-1221.

Kluender, Keith R., Randy L. Diehl \& Beverly A. Wright. 1988. Vowel-length differences before voiced and voiceless consonants: An auditory explanation. Journal of Phonetics 16. 153-169.

Kohler, Klaus J. 1982. F0 in the production of lenis and fortis plosives. Phonetica 39. 199-218.

Kohler, Klaus J. 1985. F0 in the perception of lenis and fortis plosives. Journal of the Acoustical Society of America 78(1). 21-32.

Kong, Eun Jong, Mary E. Beckman \& Jan Edwards. 2012. Voice onset time is necessary but not always sufficient to describe acquisition of voiced stops: The cases of Greek and Japanese. Journal of Phonetics 40. 725744.

Kortlandt, Frederik. 1977. Historical laws of Baltic accentuation. Baltistica 13(2). 319-330.

Kortlandt, Frederik. 1988. Remarks on Winter's Law. Dutch Contributions to the Tenth International Congress of Slavists. Sofia. Linguistics (Studies in Slavic and General Linguistics 11) 387-396.

Kortlandt, Frederik. 2009. Winter's Law again. In Frederik Kortlandt (ed.), Baltica \& balto-slavica (leiden studies in indo-european 16), 73-76. Rodopi.

Lehiste, Ilse. 1976. Influence of fundamental frequency pattern on the perception of duration. Journal of Phonetics 4(2). 113-117.

Lisker, Leigh. 1986. "voicing" in English: A catalogue of acoustic features signaling /b/ versus /p/ in trochees. Language and Speech 29(1). 2-11.

Luce, Paul A. \& Jan Charles-Luce. 1985. Contextual effects on vowel duration, closure duration, and the consonant/vowel ratio in speech production. Journal of the Acoustical Society of America 78(6). 1949-1957.

Maddieson, Ian. 1977. Further studies on vowel length before aspirated consonants. UCLA Working Papers in Phonetics 38. 82-90.

Maddieson, Ian. 1985. Phonetic cues to syllabification. In Victoria Fromkin (ed.), Phonetic linguistics, 203-221. Academic Press.

Maddieson, Ian \& Jack Gandour. 1976. Vowel length before aspirated consonants. UCLA Working Papers in Phonetics 31. 47-52. 
Matasović, Ranko. 1995. A re-examination of Winter's Law in Baltic and Slavic. Lingua Posnaniensis 37. 57-70.

Mikuteit, Simone \& Henning Reetz. 2007. Caught in the ACT: The timing of aspiration and voicing in East Bengali. Language and Speech 50(2). 247-277.

Mitleb, Fares. 1984. Voicing effect on vowel duration is not an absolute universal. Journal of Phonetics 12. 23-27.

Mohr, Burckhard. 1971. Intrinsic variations in the speech signal. Phonetica 23. 65-93.

Ohala, Manjari \& John J. Ohala. 1992. Phonetic universals and Hindi segment duration. In John Ohala, Terrance Nearey, Bruce Derwing, Megan Hodge \& Grace Wiebe (eds.), Proceedings of the international conference on spoken language processing, Banff, 12-16 October 1992, 831834.

Patri, Sylvain. 2005. Observations sur la loi de Winter. Historische Sprachforschung 118. 269-293.

Peterson, Gordon E. \& Ilse Lehiste. 1960. Duration of syllable nuclei in English. Journal of the Acoustical Society of America 32(6). 693-703.

Pierce, Jonathan W. 2007. PsychoPy - Psychophysics software in Python. Journal of Neuroscience Methods 162. 8-13.

Port, Robert F., Salman Al-Ani \& Shosaku Maeda. 1980. Temporal compensation and universal phonetics. Phonetica 37. 235-252.

Raphael, Lawrence J., Michael F. Dorman, Frances Freeman \& Charles Tobin. 1975. Vowel and nasal duration as cues to voicing in word-final stop consonants: Spectrographic and perceptual studies. Journal of Speech, Language, and Hearing Research 18(3). 389-400.

Rasmussen, Jens Elmegård. 1992. Winter's Law of Balto-Slavic lengthening: An unnatural fact? Copenhagen Working Papers in Linguistics 2. 63-77. Reprinted in Selected papers in Indo-European Linguistics 2, Part 2, 527-539. Museum Tusculanum Press, 1999.

Reddy, K. Nagamma. 1988. The duration of Telugu speech sounds: An acoustic study. IETE Journal of Research 34(1). 57-63.

Savithri, S.R. 1986. Durational analysis of Kannada vowels. Journal of Acoustical Society of India 14(2). 34-31.

Schiefer, Lieselotte. 1992. Trading relations in the perception of stops and their implications for a phonological theory. In Gerard J. Docherty \& D. Robert Ladd (eds.), Papers in Laboratory Phonology II: Gesture, segment, prosody, 296-313. Cambridge University Press.

Sharf, Donald J. 1964. Vowel duration in normal and whispered speech. Language and Speech 7. 89-97. 
Shintani, Toshihiro. 1985. On Winter's Law in Balto-Slavic. Arbejdspapirer udsendt af Kobenhavns Universitet (APILKU) 5. 273-296.

Solé, Maria-Josep. 2007. Controlled and mechanical properties in speech: A review of the literature. In Maria-Josep Solé, Patrice Speeter Beddor \& Manjari Ohala (eds.), Experimental approaches to phonology, 302-321. Oxford University Press.

Stevens, Kenneth N. \& Dennis H. Klatt. 1974. Role of formant transitions in the voiced-voiceless distinction for stops. Journal of the Acoustical Society of America 55(3). 653-659.

Summers, W. Van. 1987. Effects of stress and final-consonant voicing on vowel production: Articulatory and acoustic analyses. Journal of the Acoustical Society of America 82(3). 847-863.

Summers, W. Van. 1988. F1 structure provides information for finalconsonant voicing. Journal of the Acoustical Society of America 84(2). 485-492.

Umeda, Noriko. 1975. Vowel duration in American English. Journal of the Acoustical Society of America 58(2). 434-445.

Umeda, Noriko. 1977. Consonant duration in American English. Journal of the Acoustical Society of America 61(3). 846-858.

Vicenik, Chad. 1975. An acoustic study of Georgian stop consonants. Journal of the International Phonetic Association 40(1). 59-92.

Warner, Natasha, Allard Jongman, Joan Sereno \& Rachèl Kemps. 2004. Incomplete neutralization and other sub-phonemic duration differences in production and perception: Evidence from Dutch. Journal of Phonetics 32. 251-276.

Winter, Werner. 1978. The distribution of short and long vowels in steps of the type Lith. ésti : vèsti : mèsti and OCS jasti : vesti : mesti in Baltic and Slavic languages. In Jacek Fisiak (ed.), Recent developments in historical phonology (Trends in linguistics: Studies and monographs 4), 431-446. Mouton.

Yoneyama, Kiyoko \& Mafuyu Kitahara. 2014. Voicing effect on vowel duration: Corpus analyses of Japanese infants and adults, and production data of English learners. Journal of the Phonetic Society of Japan 18(1). 30-39.

Yu, Alan. 2010. Tonal effects on perceived vowel duration. Laboratory Phonology 10. 151-168. 